\title{
INTEGRATING GIS WITH F-AHP FOR LOCATING A SINGLE FACILITY
}

\author{
İsmail ÖNDEN \\ Transportation and Logistics Management Research Group, The Scientific and Technological Research Council \\ of Turkey (TUBITAK), Turkish Management Sciences Institute (TUSSIDE), Turkey
}

Received 14 April 2015; revised 18 August 2016; accepted 3 December 2016

\begin{abstract}
Location selection problems stand out as popular research topics. Due to the popularity, different solution approaches emerged in the literature. Multi-criteria Decision Making (MCDM) techniques are examples of the solution approaches and they are frequently used because of their ordering capability in ranking the decision alternatives and success in representing decision makers' experiences. On the other hand, Geographic Information Systems (GIS) is able to perform different spatial data analysis and provide geographic material. To reach a better decision, integration of experts' opinions and certain geographic information derived from GIS is necessary. Within this context, in this paper, integration of the GIS abilities with Fuzzy Analytic Hierarchy Process (F-AHP) is discussed with two different integration methodologies for locating a single facility. A hypothetical case study is provided to determine a location problem, which focuses on logistics activities. The results have shown that both proposed methodologies are able to order location alternatives in multiple criteria environments.
\end{abstract}

Keywords: spatial multi-criteria decision making, GIS, F-AHP, spatial analysis, spatial statistics, location analysis.

\section{Introduction}

Decision making has been an interesting topic to researchers for long-time and different approaches are employed for the research purposes. Within this context, Multi-Criteria Decision Making (MCDM) approaches are frequently used as solution tools to evaluate and solve different problem types (Dağdeviren 2008; Zolfani et al. 2013). In addition to various study topics, location selection problems have also been a popular research area for Multi-Criteria (MC) approaches. Different location problem types are investigated with MCDM techniques (Chou et al. 2008; Kuo et al. 2002; Lin, Tsai 2009; Soltani, Marandi 2011), and the results are shown that MC approaches are capable of dealing with different decision environments for a wide range of the location problems.

Spatial MCDM (S-MCDM) is a distinct topic in MCDM approach, which combines abilities of the GIS/ Spatial Analysis (GIS/SA) and MCDM techniques. The advantage of the S-MCDM is producing certain judgment by using geographic information systems' (GIS) analytic abilities over expert's decisions subjectivity. Due to this advantage, it has been a solution approach and there are different applications in the literature for location problems with spatial MC approaches (Delgado, Sendra 2004;
Malczewski 1999; Zucca et al. 2008). As examples of the approach, Vahidnia et al. (2009) investigated the proper locations for hospital facilities using Fuzzy Analytic Hierarchy Process (F-AHP) and GIS analyses. Eldemir and Onden (2016) conducted analysis to evaluate the land suitability based on a F-AHP and GIS abilities for a hospital location. Önden et al. (2018) evaluated logistics center locations suitability in metropolitan areas. Brody et al. (2006) used MC approach for site suitability analysis, which identified a potential conflict associated with oil and gas exploration in Texas coastal waters. Jankowski and Richard (1994) proposed a multi-step methodology, which uses a spatial MC approach for route selection.

In addition to spatial decision approaches, Tobler (1970) has expressed that, "everything is related to everything else, but near things are more related than distant things" to express the relationship between the attributes in geography. After Tobler's study, this statement is accepted as the first law of the geography and has even empirically been proven by Hecht and Moxley (2009). This statement is also true for the MCDM approaches when the geographic decision criteria are considered for reaching a location decision. For representing this relevance the

*Corresponding author. E-mails: ismail.onden@tubitak.gov.tr, ismailonden@gmail.com 
distances to the decision parameters and their impacts should be considered to reach the location decision.

The main aim of the study is to describe different ways of integration of GIS abilities with Buckley's F-AHP to reach decision for a single facility location. Within this context, two different methodological approaches are discussed and the study is elaborated with experimentations. Logistics center location decision problem is considered as example and the suggested methodologies are applied for the problem. In literature some guiding studies and partially integrated solution approaches are available. Önden et al. (2015) considered the parameters have influence logistics center decision and gave a decision criteria list that can be used for location selection problem. Özceylan et al. (2016) applied a spatial MCDM approach based on the Technique for Order of Preference by Similarity to Ideal Solution (TOPSIS), Analytical Network Process (ANP) and GIS for evaluation of freight villages to determine the best alternative in their alternative set using thirteen decision parameters. Elevli (2014) used fuzzy Preference Ranking Organization METHod for Enrichment Evaluation (Fuzzy-PROMETHEE) technique for a logistics freight center location. Kampf et al. (2011) used a weighted sum approach to determine the priorities of the considered decision criteria then combined the results with the logistics center location decision. Önden et al. (2018) evaluated on-going logistics center investment decisions' spatial convenience with a fuzzy spatial decision analysis approach with using F-AHP and GIS/SA.

Although, in literature, there are some studies available that deal with spatial characteristics and complexities in decision making approaches; the integration of F-AHP with GIS/SA needs more attention. This does contributes to the literature by discussing the integration of F-AHP with GIS' different analyses such as Spatial Analysis (SA), spatial statistics and network analysis. Contributing the vast decision making literature in fuzzy logic aspect or GIS is seen as out of scope of the study. However, the paper contributes the decision analysis literature with a clear statement of using GIS analytic tools to reach a location decision in different location problem type considerations.

This paper is organized as follows: the next section describes the proposed methodology step by step. The section that follows methodology section explains the details of Euclidean distance analysis, hot spot analysis, service area calculations and F-AHP. Then, in the application section, the proposed methodology is applied for siting a new logistics facility. In that section, the steps are clearly expressed while taking the results and sensitivity issues into the consideration. The last section is the conclusion section, which has the final discussions and it summarizes the paper with the advantages of the methodology.

\section{Suggested methodologies}

In this study, we describe two methodologies to express how GIS/SA can be integrated with F-AHP for location problems, which focus on integrating $\mathrm{MC}$ approaches with
SA and network analysis to solve various types of location analysis problems. The aim of the proposed methodologies is to take GIS analysis abilities and use them to develop information where certain statement can be reached. With this approach, it is possible to create certain information about spatial features in the decision environment. Conversion of geographic preferences to triangular fuzzy numbers is discussed, and a table is given for relevant studies. In addition to the new methodological approaches to location selection problems, the paper uses distance analysis, service areas, hot spot analysis, which is a clustering approach with MCDM approaches.

The first approach uses the F-AHP approach for alternative comparisons based on the created geographic information with the GIS. Within this approach, the idea of using the GIS findings to convert to triangular fuzzy numbers and find the preference orders of the alternatives with the pair-wise comparisons. The second approach is using the F-AHP approach for decision criteria comparisons and priority creation. The GIS is using the calculated priorities to reach the suitability map that represents the decision preferences of the candidate location alternatives.

The suggested methodologies show both similarities and dissimilarities during the decision making process. As similarities, it can be said that these two solution approaches are using same GIS analysis results as inputs and integrating GIS and F-AHP in the step-wise structure to reach the best location decision. The major difference between Methods I and II is the use of the F-AHP. Method I takes the GIS results, converts them to scores from the results, fuzzifies the numbers, then inserts the scores into F-AHP and reaches a conclusion. Method II uses F-AHP as a weight calculator of the decision criteria. The Method I digitizes the outputs of the analyses and combines with F-AHP with triangular numbers. The second method combines GIS outputs with the GIS overlaying tool to create the suitability map that represents the decision preferences. After both of the decision analysis, the reached decision is evaluated by a sensitivity analysis.

\subsection{Method I: using GIS outcomes in the F-AHP}

Figure 1 is illustrating the steps of the Method I. Within this methodology, the GIS is used to create geographic information via GIS' analytic abilities for alternative comparisons in F-AHP. The aim of using these techniques is converting geographic data into geographic information to resolve the subjectivity when a geographical metric is used.

Hot spot analysis, service area calculation and Euclidean distance analysis are accepted as useful techniques, which are able to generate data for F-AHP comparisons. Hot spot analysis, which is a spatial statistics tool is used to determine the hot and cold spots of the focused criteria in study area, service area calculation is suggested to create service areas on the existing transportation network structure with network analysis and the Euclidean distance analysis, which is an ability of the SA is proposed to 


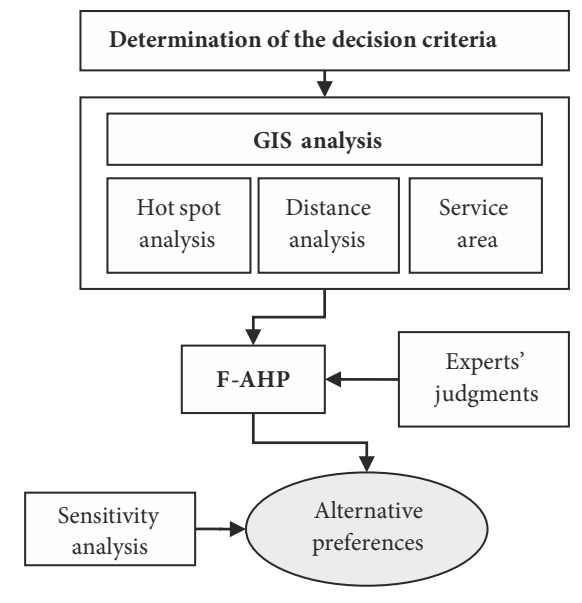

Figure 1. Explanation of the Method I

measure attractiveness levels of the decision criteria based on the exact location of the focused facilities. Accordingly, it can be said that GIS approaches convert geographic data into geographic information to create a certain statement about decision criteria and decision alternatives.

After GIS calculations, the F-AHP reaches the preferences of the alternative nodes. In this step, experts' judgments are using for the comparisons of the criteria, which cannot be represented with geographically. For the other calculation can be acquired by the GIS calculations, and with the integration of these judgments, F-AHP finds the results.

\subsection{Method II: using F-AHP priorities in suitability analysis}

The second approach is using GIS to create a suitability map that represents the suitability levels of the existing alternative nodes. The Figure 2 is explaining the analysis structure of the Method II. The suitability concept is expressing the land convenience levels for the new considered facility. Within this approach, firstly decision criteria should be determined by the experts who have experience in the research topic. Then these experts should complete the pairwise comparisons to measure the weights of the decision criteria. On the other hand, the GIS is suggested to measure the spatial characteristics of the decision criteria and hot spot analysis, distance analysis and service area calculations are expressed as data analysis approaches that will be combined the calculated weights values with overlay tool to create the suitability map.

\subsection{Analysis tools used in the methodologies}

Two different location approaches are discussed in the study for siting one facility, and four different location analyses are and F-AHP analysis proposed to constitute methodologies for finalizing the location decision. This chapter is expressing the analytic background of these analyses and how the approaches should be performed to reach the location decision.

\subsubsection{Euclidean distance analysis}

One of the analysis ability of the GIS/SA is Euclidean distance analysis, which gives the chance to calculate how the geographic criteria sprawled on the plane. The distance analysis does not measure the densities of the focused attribute; it converts analysis area to raster data and separates the focused plane to the small grids to understand the closeness of the grids to the points, which belong to the decision criteria's locations. The calculation of the Euclidean distance analysis is expressed in Figure 3. After gathering the Euclidean distance values of the grids, it is necessary to reclassify the calculated maps with determined intervals for adjustment of the criteria maps.

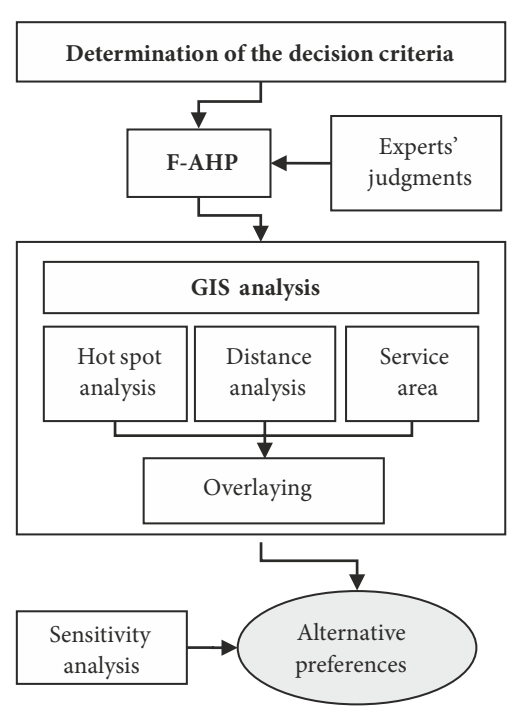

Figure 2. Explanation of the Method II
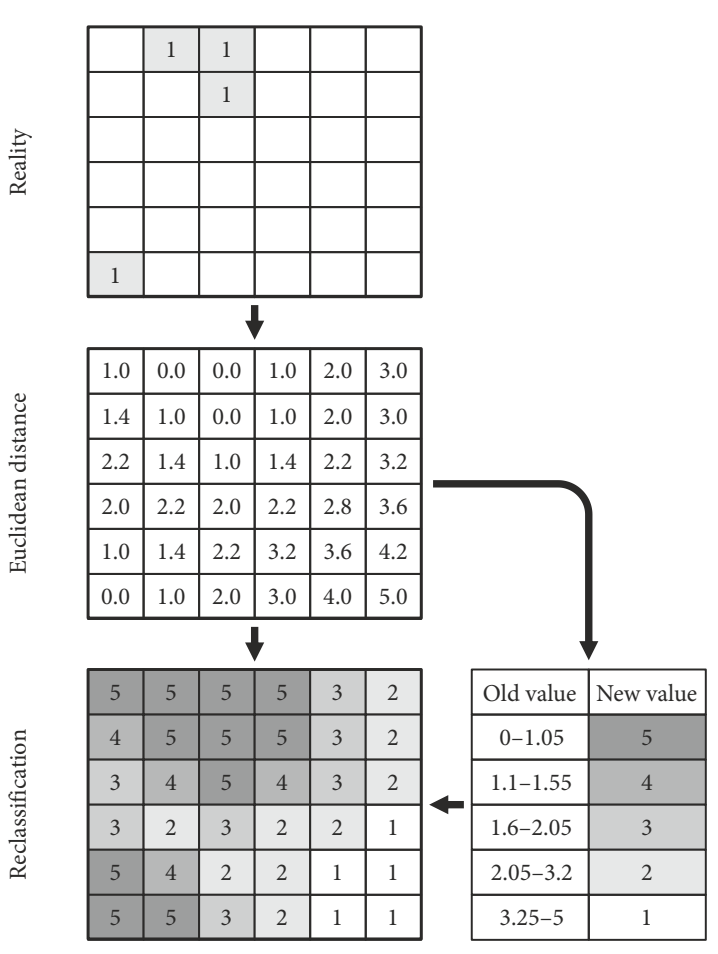

Figure 3. Reclassification and Euclidean distance 
The reclassified maps show how the decision criteria affect the study area and there are different ways to reach the reclassified maps. Despite the fact that there are different calculation techniques in the classification, using natural breaks is seen as the reasonable one for calculating the process, which represents the characteristics of the scattering of the criteria on the plane (Jenks 1967). In Figure 3, a stepwise illustration of the Euclidean distance with a basic application is presented for a better understanding. The calculated values in the reclassified maps show accordance with conversion SA analysis outputs when 9 intervals are used and when the Saaty's 1-9 scale is used in the pairwise comparison step.

\subsubsection{Hot spot analysis}

Hot spot analysis is a method used for finding the hot and cold spots on the plane statistically and clustering of the separated subgroups of the study area based on spatial autocorrelation and Moran's I structures. In addition to the harmony of this technique with the proposed methodology, there are existing studies based on the hot spot analysis for different research applications. Erdogan et al. (2008) used the GIS abilities to deter-mine the traffic accident hot spots of Afyonkarahisar city. Levine (2006) used spatial autocorrelation structure and hot spot analysis for crime mapping. Truong and Somenahalli (2011) used GIS to identify hot spots for pedestrian-vehicle crash with gathered 13 years data under spatial correlation, Moran's I, and Getis-Ord Gi* rules.

Moran's I index should be used to measure the spatial autocorrelation to examine the spatial patterns of the study area. Moran's I measure the similarities of the attributes and calculate an index, which consists of location proximities. There are different approaches to measuring the location proximities, and zone of indifference is one of the options for calculation. The stated index can be calculated using the following Equation (1) where $w_{i j}$ is the proximity weight of location $i$ and location $j$ (when $w_{i i}=$ $0 ; x_{i}$ is the severity index at location $j ; x$ is the global mean value; $n$ is the total number of focused location) (Truong, Somenahalli 2011):

$$
I=\frac{n \cdot \sum_{i=1}^{n} \sum_{j=1}^{n} w_{i j} \cdot\left(x_{i}-\bar{x}\right) \cdot\left(x_{j}-\bar{x}\right)}{\left(\sum_{i=1}^{n} \sum_{j=1}^{n} w_{i j}\right) \cdot\left(\sum_{i}^{n}\left(x_{i}-\bar{x}\right)^{2}\right)} .
$$

Moran's I statistical significance can be calculated via $Z$-score methods. In Equation (2), the expected values $E(I)$ for a random pattern, the variances $V A R(I)$ is used. Mathematical representation of the $Z$-score:

$$
Z=\frac{I-E(I)}{\sqrt{\operatorname{VAR}(I)}} .
$$

Appropriate distance threshold value should be found where the spatial autocorrelation is maximized since each data point is analysed in terms of its neighbouring data points defined by a distance threshold. To reach the maximum value, spatial autocorrelation tool should be performed several times, and the changes in the $Z$-value should be observed empirically. $Z$-value shows whether the data clustered or randomly distributed on the plane with a determined significance level.

Getis-Ord statistic (ESRI 2014; Getis, Ord 1992) is used for specifying hot spots. A high value of Getis-Ord statistic expresses the hot spots; whereas a low value shows the cold spots. The mathematical definition of the GetisOrd $\mathrm{Gi}^{*}$ statistic is given in the following Equations (3) and (4):

$$
\begin{aligned}
& G_{i}^{*}(d)=\frac{\sum_{j=1}^{n} w_{i j}(d) \cdot x_{j}}{\sum_{j=1}^{n} x_{j}} ; \\
& Z\left(G_{i}^{*}\right)=\frac{I-E(I)}{\sqrt{\operatorname{VAR}(I)}} .
\end{aligned}
$$

\subsubsection{Service area calculation}

Determining the service areas of the geographic decision criteria is a capability of the network analysis. The service areas represent the exact distances toward to the focused facility and draw a polygon to express, which areas are covered to be served by the facilities. It is proposed to calculate service areas that 1-9 preference orders for alternative calculation in the study. To be able to perform the network analysis, primarily, the existing transportation network should be created, and the specialties of the network should be represented such as U-turn policies, restricted ways, transportation network hierarchy, and so on. After building the network data set that represents the connections and the characteristics of the city transportation network, it is possible to measure the service areas of the focused facilities. The distances to the break points should be expressed by the decision makers, and based on their expressions alternatives' success levels for the decision criteria should be calculated.

\subsubsection{Overlaying}

Overlaying is suggested to be used in Method II to illustrate the preference levels of the location alternatives. The aim of using overlaying is creating an understandable output that integrates different characteristics of the decision criteria in one map. Thus, overlaying takes different raster maps that created based on Euclidean distance analysis, hot spot analysis, service area calculation and the others with their weights, combines them into one map that illustrates how desirables the sub-areas are. For the calculation of the result map, the input maps should represent same value intervals that makes the reclassification step (Figure 3 ) is a necessity before the overlaying. 


\subsubsection{F-AHP}

AHP is an analytic decision making and evaluation technique based on pairwise comparisons, which is able to find the reasonable alternative among others and evaluate the priorities of the alternatives and decision criteria's priorities. Saaty $(1980,2008)$ described the steps of the analysis and Buckley (1985) extended this technique with fuzzy approach.

The F-AHP process is described in the steps as follows.

In the first step, pairwise comparison matrices should be constructed for each criterion in the decision environment. The comparison values can be gathered by asking which criteria is more important with different approaches such as group decision making, Delphi technique, etc. The structure of the pairwise comparison matrices is expressed in Equation (5) as follows:

$$
\tilde{A}=\left[\begin{array}{cccc}
1 & \tilde{a}_{12} & \cdots & \tilde{a}_{1 n} \\
\tilde{a}_{21} & 1 & \cdots & \tilde{a}_{2 n} \\
\vdots & \vdots & \ddots & \vdots \\
\tilde{a}_{n 1} & \tilde{a}_{n 2} & \cdots & 1
\end{array}\right]=\left[\begin{array}{cccc}
1 & \tilde{a}_{12} & \cdots & \tilde{a}_{1 n} \\
\frac{1}{\tilde{a}_{12}} & 1 & \cdots & \tilde{a}_{2 n} \\
\vdots & \vdots & \ddots & \vdots \\
\frac{1}{\tilde{a}_{1 n}} & \frac{1}{\tilde{a}_{2 n}} & \cdots & 1
\end{array}\right] .
$$

In this study, we used GIS results as $\tilde{a}_{i j}$ values with the Saaty's scale.

$$
\tilde{a}_{i j}=\left\{\begin{array}{l}
a_{1} ; \\
a_{2} ; \\
a_{3},
\end{array}\right.
$$

where:

$a_{1} \rightarrow \tilde{1}, \tilde{3}, \tilde{5}, \tilde{7}, \tilde{9}$, when criterion $i$ has relative importance to criterion $j$;

$a_{2} \rightarrow 1$, when $i=j$, when $i=j$;

$a_{3} \rightarrow \tilde{1}^{-1}, \tilde{3}^{-1}, \tilde{5}^{-1}, \tilde{7}^{-1}, \tilde{9}^{-1}$, when criterion $i$ has relative less importance to criterion $j$.

In pairwise comparison step, there is a fuzzify part of the outputs of the GIS analysis' results. GIS analyses are done to measure the performances of the geographic decision criteria, and the outputs of the SA are based on crisp values. A table is developed to convert these calculated scores into triangular fuzzy values and the whole table is expressed in Table 2 based on the Saaty's scale. Saaty's scale has close intervals between fuzzy numbers, which make it proper to use in location evaluation process. It is possible to use a different scale in evaluation such as Mon et al. (1994). Saaty's fuzzy scale for evaluation of the geographic criteria is given in Table 1.
In the second step, to find the weights formula 6 should be used in the calculation based on the Buckley's F-AHP approach (Buckley 1985):

$$
\begin{aligned}
& \tilde{r}_{i}=\left(\tilde{a}_{i 1} \otimes \tilde{a}_{i 1} \otimes \ldots \otimes \tilde{a}_{i n}\right)^{\frac{1}{n}} ; \\
& \tilde{w}_{i}=\tilde{r}_{i} \otimes\left(\tilde{a}_{i 1} \oplus \tilde{a}_{i 1} \oplus \ldots \oplus \tilde{a}_{i n}\right)^{-1},
\end{aligned}
$$

where: $\tilde{a}_{i n}$ is the fuzzy comparison values of criterion $i$ to criterion $n ; \tilde{r}_{i}$ geometric mean of fuzzy comparison value of criterion $i$ to each criterion; $\tilde{w}_{i}$ is the fuzzy weight of the fuzzy weight of the $i$-th criterion, which can be shown by triangular fuzzy numbers, $\tilde{w}_{i}=\left(L w_{i}, M w_{i}, U w_{i}\right)$, where stands $L$ for lower, $M$ for middle and $U$ for upper (Hsieh et al. 2004).

Additionally, F-AHP approach is suggested for integration of the GIS in the Methods I and II. In the Method II F-AHP outputs are used as inputs of the GIS/suitability analysis. In the Method I, F-AHP is suggested to compare alternative comparisons. GIS findings are accepted as the values that represents the alternative comparisons. These numbers are required to be converted to the fuzzy numbers based on Table 1. Table 2 is given to express how these converted values form the pairwise comparison table.

In the next section, an application for illustrating the F-AHP technique is given for a logistics facility location selection problem to express the steps of the methodology and to illustrate how the SA should be performed, explaining how the crisp numbers should be converted to the fuzzy numbers.

\begin{tabular}{|c|c|c|c|c|c|c|c|c|c|}
\hline$j / i$ & 1 & 2 & 3 & 4 & 5 & 6 & 7 & 8 & 9 \\
\hline 1 & $(1,1,1)$ & $(0.33,0.50,1)$ & $(0.25,0.33,0.50)$ & $(0.20,0.25,0.33)$ & $(0.17,0.20,0.25)$ & $(0.14,0.17,0.20)$ & $(0.12,0.14,0.17)$ & $(0.11,0.12,0.14)$ & $(0.11,0.11,0.11)$ \\
\hline 2 & $(1,2,3)$ & $(1,1,1)$ & $(0.33,0.50,1)$ & $(0.25,0.33,0.50)$ & $(0.20,0.25,0.33)$ & $(0.17,0,20,0.25)$ & $(0.14,0.17,0.20)$ & $(0.125,0.14,0.17)$ & $(0.11,0.12,0.14)$ \\
\hline 3 & $(2,3,4)$ & $(1,2,3)$ & $(1,1,1)$ & $(0.33,0.50,1)$ & $(0.25,0.33,0.50)$ & $(0.20,0.25,0.33)$ & $(0.17,0.20,0.25)$ & $(0.14,0.17,0.20)$ & $(0.12,0.14,0.17)$ \\
\hline 4 & $(3,4,5)$ & $(2,3,4)$ & $(1,2,3)$ & $(1,1,1)$ & $(0.33,0.50,1)$ & $(0.25,0.33,0.50)$ & $(0.20,0.25,0.33)$ & $(0.17,0.20,0.25)$ & $(0.14,0.17,0.20)$ \\
\hline 5 & $(4,5,6)$ & $(3,4,5)$ & $(2,3,4)$ & $(1,2,3)$ & $(1,1,1)$ & $(0.33,0.50,1)$ & $(0.25,0.33,0.50)$ & $(0.20,0.25,0.33)$ & $(0.17,0.20,0.25)$ \\
\hline 6 & $(5,6,7)$ & $(4,5,6)$ & $(3,4,5)$ & $(2,3,4)$ & $(1,2,3)$ & $(1,1,1)$ & $(0.33,0.50,1)$ & $(0.25,0.33,0.50)$ & $(0.20,0.25,0.33)$ \\
\hline 7 & $(6,7,8)$ & $(5,6,7)$ & $(4,5,6)$ & $(3,4,5)$ & $(2,3,4)$ & $(1,2,3)$ & $(1,1,1)$ & $(0.33,0.50,1)$ & $(0.25,0.33,0.50)$ \\
\hline 8 & $(7,8,9)$ & $(6,7,8)$ & $(5,6,7)$ & $(4,5,6)$ & $(3,4,5)$ & $(2,3,4)$ & $(1,2,3)$ & $(1,1,1)$ & $(0.33,0.50,1)$ \\
\hline 9 & $(9,9,9)$ & $(7,8,9)$ & $(6,7,8)$ & $(5,6,7)$ & $(4,5,6)$ & $(3,4,5)$ & $(2,3,4)$ & $(1,2,3)$ & $(1,1,1)$ \\
\hline
\end{tabular}

Table 1. Fuzzy scale

\begin{tabular}{|c|l|c|c|}
\hline $\begin{array}{c}\text { Fuzzy } \\
\text { number }\end{array}$ & Linguistic scales & $\begin{array}{c}\text { Scale of } \\
\text { triangular } \\
\text { fuzzy number }\end{array}$ & $\begin{array}{c}\text { Reciprocal } \\
\text { triangular fuzzy } \\
\text { numbers }\end{array}$ \\
\hline$\tilde{1}$ & extremely strong & $(9,9,9)$ & $(0.11,0.11,0.11)$ \\
\hline$\tilde{2}$ & intermediate value & $(7,8,9)$ & $(0.11,0.13,0.14)$ \\
\hline$\tilde{3}$ & very strong & $(6,7,8)$ & $(0.13,0.14,0.17)$ \\
\hline$\tilde{4}$ & intermediate value & $(5,6,7)$ & $(0.14,0.17,0.20)$ \\
\hline$\tilde{5}$ & strong & $(4,5,6)$ & $(0.17,0.20,0.25)$ \\
\hline$\tilde{6}$ & intermediate value & $(3,4,5)$ & $(0.20,0.25,0.33)$ \\
\hline$\tilde{7}$ & moderately strong & $(2,3,4)$ & $(0.25,0.33,0.50)$ \\
\hline$\tilde{8}$ & intermediate value & $(1,2,3)$ & $(0.33,0.50,1.00)$ \\
\hline$\tilde{9}$ & equally strong & $(1,1,1)$ & $(1.00,1.00,1.00)$ \\
\hline
\end{tabular}

Table 2. GIS outputs conversation to fuzzy numbers $(L, M, U)$ 


\subsection{Sensitivity analysis}

Sensitivity analysis is crucial to understand how decisions change under different circumstances. Due to its importance sensitivity analysis is also commonly used in spatial MC decision evaluations (Chiang et al. 2007; Delgado, Sendra 2004; Eldemir, Onden 2016).

There are two approaches in sensitivity analysis of spatial MC decisions (Eldemir, Onden 2016; Jankowski 1995). First approach is taking all alternatives into consideration with changed priorities. The second is considering alternative pairs and evaluate the changes. In this study, impacts of criteria changes over calculated alternative preferences are explored by sensitivity analysis. Thus considering all alternatives became suitable for the study. It is suggested to create scenarios that reflect the all possible changes in priorities in long term. The scenarios that are generated will differ from application to application. Thus scenarios will unique for each sector, health, logistics, production and etc. Thus, each location problem should be considered by the experts who have experience to related research area.

\section{Application}

Istanbul is the economical capital of the Turkey and also its region. Due to high economic dynamism and international connections, logistics activities are in increasing trend. Hence, new logistics facilities are needed to meet the increasing demand. The proposed methodology can be used to determine the convenient areas for logistics facilities such as warehouses, truck parks, etc.

Due to new facility needs and economic growth of the region, Istanbul is selected as the study area. Within this context, three alternative locations are determined as the candidate sites for the investment decision. Locations of the logistics companies, motorway network, seaport nodes, and railway network are selected as the decision parameters, and their priorities (Table 3 ) are taken from the previous studies.

Table 3. Weights of the decision criteria

\begin{tabular}{|l|c|}
\hline \multicolumn{1}{|c|}{ Criteria } & Weight by Kampf et al. (2011) \\
\hline Airway & 0.12 \\
\hline Railway & 0.36 \\
\hline Highway & 0.36 \\
\hline Seaway & 0.09 \\
\hline Population & 0.07 \\
\hline
\end{tabular}

\subsection{GIS}

This section expresses the GIS analyses that were given in the methodology section. The outputs of the analyses will be used in calculations of both the Methods I and II.

\subsubsection{Distance analysis}

Euclidean distance analysis is applied to measure all alternatives' proximities to considered spatial decision criteria.
Euclidean distance analysis is used to evaluate airway, railway and highway decision criteria and output maps are created.

The analysis takes the considered decision criteria's vector data as input and produces a raster distance map, which gives whole study area's proximity values towards to the considered data. To be able to measure these values, study area, which is a raster data set is separated to 113500 grids sized $200 \mathrm{~m}^{2}$. The application is applied with GIS software and result maps were obtained. The raster maps are reclassified based on natural break point rule and the reclassified maps are used to determine the performances of the considered location alternatives. The outputs of the reclassification process are illustrated in Figure 4. The suitability values are converted to triangular fuzzy numbers and then converted to judgments in comparison table of F-AHP in Method I as expressed in Table 2. The maps are used as input maps for suitability analysis expressed in Method II.

\subsubsection{Hot spot analysis}

For mapping clusters of spatial hot and cold spots, firstly the pattern is analysed. With using Moran's I-statistics, which is a spatial autocorrelation method, it is possible to examine if the considered dataset is clustered. For applying a cluster approach, it is necessary the dataset has a clustered structure. The existing land use and population are used as inputs. The data are gathered from the Turkish Statistical Institute and vector data are generated. The study area is separated into 967 parts according to the borders of the districts of the Istanbul and discrete population is spatially joined to the data. During the pattern analysis zone of indifference is used for conceptualization of spatial relationship. And Euclidean distance is used as distance method. The results of the spatial autocorrelation showed that the population dispersion is clustered and the use of hot spot analysis is convenient. After finding suitability of using a clustering algorithm, hot spot analysis is used to evaluate the spatial characteristics of the population.

Getis-Ord Gi* tool of hot spot analysis is performed with the same data where using the clustering algorithm was found as convenient. $I$-statistics is calculated for each discrete value and the results are taken as inputs of the hot spot analysis. The result of the hot spot analysis is illustrated in Figure 5. The analysis is performed with threshold distance values, which is $7000 \mathrm{~m}$ where the $Z$-value of spatial autocorrelation is maximized.

Result of the clustering algorithm gave the demand classifications. The generated result is an input as explained in the methodology section. The cluster values are converted to the triangular fuzzy numbers to be able to use in F-AHP technique in Method I. The output map is used as an input map in overlaying with the other criteria maps in the Method II to represent the land suitability.

\subsubsection{Service area calculation}

Seaports' service areas are used for the alternative comparison. Thus 9 service areas are determined based on the 
distance analysis. 5, 10, 20, 30, 40, 50, 60, 70 and $100 \mathrm{~km}$ distances are accepted as the borders and these areas are calculated as the illustration in the Figure 6. In the comparisons, the proximities to the facilities are accepted as positive and quantified based on this assumption in the calculations. The obtained service areas are used in the discussed methodologies. The output vector map that represents the service area is converted to a raster map and imported to suitability analysis suggested in Method I. The generated 9 service areas converted to fuzzy numbers in Method II. During calculations, $\tilde{9}$ equals to the service area $5 \mathrm{~km}$, and $\tilde{1}$ to $100 \mathrm{~km}$, and the comparisons are converted to triangular fuzzy numbers in comparisons based on the judgments expressed in the Table 2 .

\subsection{Method I}

Three location alternatives are evaluated with the Method I. The first step of the solution approach is determi- nation of the decision criteria of the location selection process. As the determinants of the logistics center location problem statistically distribution of the logistics companies and transportation networks are accepted. As expressed in the previous parts, GIS is used for alternative comparisons, and hot spots of the logistics facilities, Euclidean distances of the motorway network and railway network, and service areas of the seaports are used for the selection. Figures 6-8. The maps are illustrating the alternative performances in the analyses, and the gathered values are converted firstly to fuzzy triangular numbers, then the pairwise comparisons. The gathered values from the GIS analyses and the converted fuzzy scores respect to these analyses are expressed in the Table 4.

Table 3 describes, the $\tilde{a}_{i j}$ value conversions based on the Table 2. Since finding the priorities of the decision criteria are not considered, the priorities are accepted equal, and have same influence on the decision environment. a)

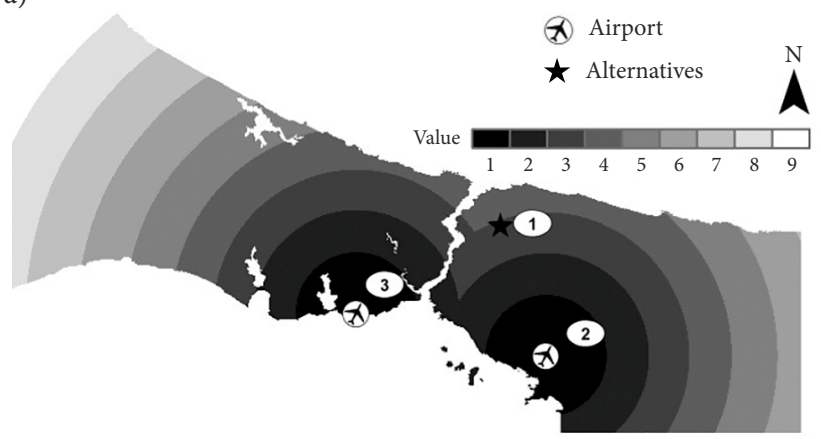

b)

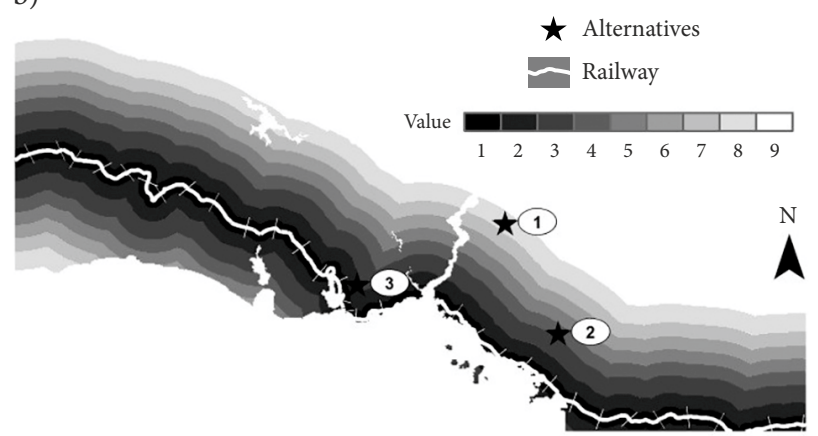

c)

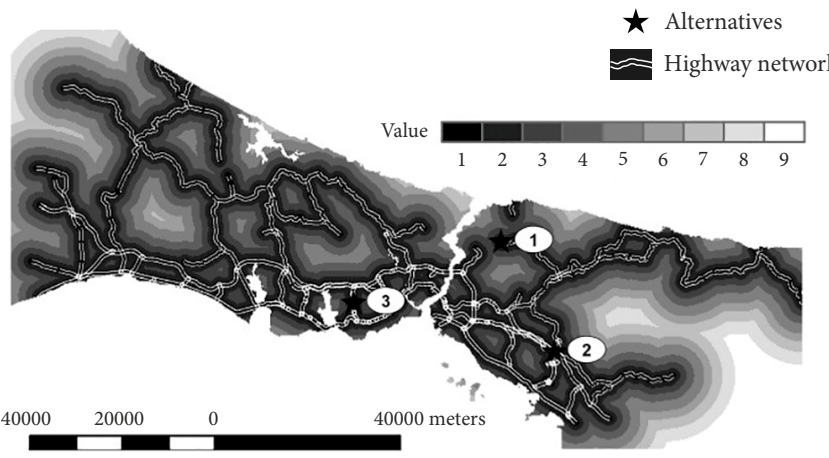

Figure 4. Results of the Euclidean distance analyses: a - proximities to airports; $\mathrm{b}$ - proximities to railway; $\mathrm{c}$ - proximities to highway network

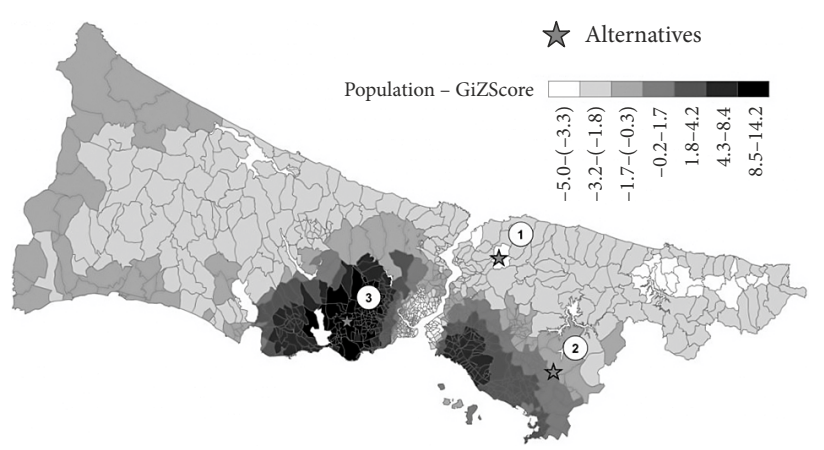

Figure 5. Result of the hot spot analysis for population

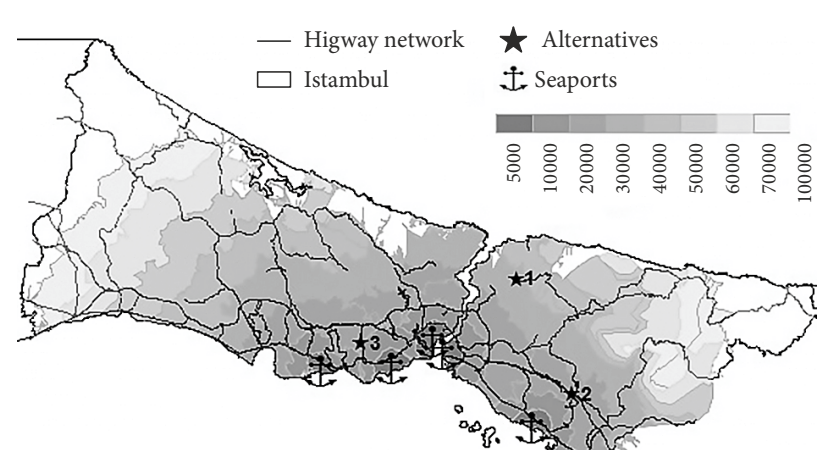

Figure 6. Service area calculation results 
Table 4. Alternative scores gathered from the criteria maps

\begin{tabular}{|l|c|c|c|c|c|c|}
\hline \multirow{2}{*}{ Criteria } & \multicolumn{2}{|c|}{ Alternative I } & \multicolumn{2}{c|}{ Alternative II } & \multicolumn{2}{c|}{ Alternative III } \\
\cline { 2 - 7 } & Value & $\begin{array}{c}\text { Fuzzy } \\
\text { score }\end{array}$ & Value & $\begin{array}{c}\text { Fuzzy } \\
\text { score }\end{array}$ & Value & $\begin{array}{c}\text { Fuzzy } \\
\text { score }\end{array}$ \\
\hline Highway & 1 & $\tilde{9}$ & 1 & $\tilde{9}$ & 1 & $\tilde{9}$ \\
\hline Railway & 3 & $\tilde{7}$ & 2 & $\tilde{8}$ & 1 & $\tilde{9}$ \\
\hline Seaway & 6 & $\tilde{4}$ & 4 & $\tilde{7}$ & 4 & $\tilde{7}$ \\
\hline Population & 9 & $\tilde{1}$ & 3 & $\tilde{7}$ & 1 & $\tilde{9}$ \\
\hline Airway & 3 & $\tilde{7}$ & 1 & $\tilde{9}$ & 1 & $\tilde{9}$ \\
\hline
\end{tabular}

Thus, the comparison matrix is built to compare alternatives based on the calculated criteria maps. The criteria scores are gathered from the Euclidean distance and hot spot maps, which are illustrated in Figure 6-8 expressed in Table 3. The next step is conducting the pairwise comparison matrix. Table 5 includes the triangular fuzzy numbers of the decision criteria and local priorities of each decision criteria.

The calculations are done with the values expressed in Table 5. The results showed the alternatives A1, A2, A3 had the values of $0.252,0.312$, and 0.391 in sequence. The results show that the $\mathrm{A} 3$ is the most convenience place for siting the new facility. The second alternative's location is following the $\mathrm{A} 3$ and the $\mathrm{A} 1$ is the worst place among the alternatives.

Table 5. Fuzzy scores based pairwise comparison of the decision alternatives

\begin{tabular}{|c|c|c|c|c|}
\hline Highway & A1 & $\mathrm{A} 2$ & A3 & Priorities \\
\hline A1 & $\tilde{1}$ & $\tilde{1}$ & $\tilde{1}$ & 0.333 \\
\hline $\mathrm{A} 2$ & $\tilde{1}$ & $\tilde{1}$ & $\tilde{1}$ & 0.333 \\
\hline A3 & $\tilde{1}$ & $\tilde{1}$ & $\tilde{1}$ & 0.333 \\
\hline Railway & A1 & A2 & A3 & Priorities \\
\hline A1 & $\tilde{1}$ & $\widetilde{1 / 2}$ & $\widetilde{1 / 3}$ & 0.166 \\
\hline $\mathrm{A} 2$ & $\tilde{2}$ & $\tilde{1}$ & $1 / 2$ & 0.300 \\
\hline A3 & $\tilde{3}$ & $\tilde{2}$ & $\tilde{1}$ & 0.534 \\
\hline Seaway & $\mathrm{A} 1$ & $\mathrm{~A} 2$ & A3 & Priorities \\
\hline A1 & $\tilde{1}$ & $\widetilde{1 / 4}$ & $\widetilde{1 / 4}$ & 0.113 \\
\hline A2 & $\tilde{4}$ & $\tilde{1}$ & $\tilde{1}$ & 0.444 \\
\hline A3 & $\tilde{4}$ & $\tilde{1}$ & $\tilde{1}$ & 0.444 \\
\hline Population & A1 & A2 & A3 & Priorities \\
\hline Al & $\tilde{1}$ & $\tilde{7}$ & $\tilde{9}$ & 0.785 \\
\hline $\mathrm{A} 2$ & $\widetilde{1 / 7}$ & $\tilde{1}$ & $\tilde{3}$ & 0.149 \\
\hline A3 & $\widetilde{1 / 9}$ & $\widetilde{1 / 3}$ & $\tilde{1}$ & 0.067 \\
\hline Airway & A1 & $\mathrm{A} 2$ & A3 & Priorities \\
\hline A1 & $\tilde{1}$ & $\widetilde{1 / 3}$ & $\widetilde{1 / 3}$ & 0.098 \\
\hline $\mathrm{A} 2$ & $\tilde{3}$ & $\tilde{1}$ & $\tilde{1}$ & 0.283 \\
\hline A3 & $\tilde{3}$ & $\tilde{1}$ & $\tilde{1}$ & 0.283 \\
\hline
\end{tabular}

\subsection{Method II}

Method II is considering the evaluations of alternative locations to determine the best candidate in an alternative set with spatial characteristics consideration as like as Method I. As a difference from Method I, in this approach, GIS finalize the location decision via a suitability analysis. The suitability analysis takes the resulted spatial, network and spatial statistics analysis map; combines them via an overlay analysis; and creates a suitability map that expresses the convenient orders of the alternatives. The result of this analysis illustrates the decision preferences of the candidate sites on continuous plane. In other words, the results give the whole study area's suitability ranks and the obtained values are linked with alternatives.

In the study, five decision criteria are considered to reach the suitability levels of the candidate sites of logistics centers. It is accepted that each decision criteria priorities may show a variety based on their influences and Kampf's study taken as the base of the priority values (Kampf et al. 2011). The weights of the considered decision criteria are given in Table 3.

The calculated distance, hot spot and service area maps are used as inputs of the Method II analysis, and thanks to the combining capability of the overlaying, these maps are combined, and the result map is given in the Figure 7. The results showed that the $\mathrm{A} 3$ is in best alternative, the $\mathrm{A} 2$ is the second best and A1 is the last alternative for the investment decision.

Table 6. Preference order of the alternatives

\begin{tabular}{|c|c|c|c|c|}
\hline $\begin{array}{c}\text { Alterna- } \\
\text { tives }\end{array}$ & $\begin{array}{c}\text { Alternative's } \\
\text { preference } \\
\text { rank }\end{array}$ & $\begin{array}{c}\text { Method I } \\
\text { preference } \\
\text { order }\end{array}$ & $\begin{array}{c}\text { Alternative's } \\
\text { suitability } \\
\text { value }\end{array}$ & $\begin{array}{c}\text { Method II } \\
\text { preference } \\
\text { order }\end{array}$ \\
\hline A1 & 0.257 & 3 & 6 & 3 \\
\hline A2 & 0.312 & 2 & 7 & 2 \\
\hline A3 & 0.391 & 1 & 8 & 1 \\
\hline
\end{tabular}

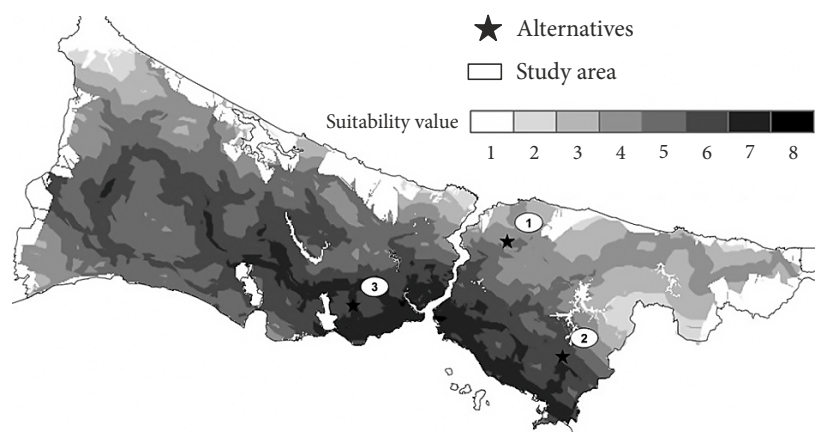

Figure 7. Result map of the method II

\subsection{Sensitivity analysis}

As explained in the methodology section, the sensitivity of the decision can be reached with considering variations of the weights of the decision criteria. Thus three scenarios are created to analyse the differences in the alternative's preference orders. The scenarios are as follows: 
1. if the all decision criteria had the same priority value (assigned weights: highway: 0.2 ; railway: 0.2 ; seaway: 0.2 ; airway: 0.2 ; population: 0.2 );

2. if the criteria related to transportation had more influential over location decision (assigned weights: highway: 0.25 ; railway: 0.25 ; seaway: 0.25 ; airway: 0.25 ; population: not considered);

3. if the population criteria were more important than other decision priorities (assigned weights: highway: 0.125 ; railway: 0.125 ; seaway: 0.125 ; airway: 0.125 ; population: 0.5 ).

The created scenarios aimed to measure how the preference orders of the location alternatives changes. Thus decision criteria weights are changed and F-AHP analysis and overlay analysis are repeated. The results of GIS/SA are illustrated in Figure 8 and the findings are given in Tables 7 and 8.

The scenarios are used to understand how the changes are affecting the results. The calculations showed that the best alternative is same with two approaches in all scenarios. However, second and third rankings showed differences.

\section{Conclusions}

This study focused on how GIS can be integrated with the F-AHP analysis. For this purpose, two methodological approaches are suggested for combining the different GIS tools with F-AHP analysis in a stepwise structure. At the end of the study, the results showed that GIS combined with F-AHP can be used as a decision making tool for location selection. The results showed that both methods reached the same preference orders for three alternatives given in Table 6. However there were differences in the success levels (preference ranks and suitability values) in the selection. The preference levels showed the third alternative is the best one with the Method I; however, according to the calculated values the second alternative reached close preference value to the best alternative. The Method II reached the same preference orders with

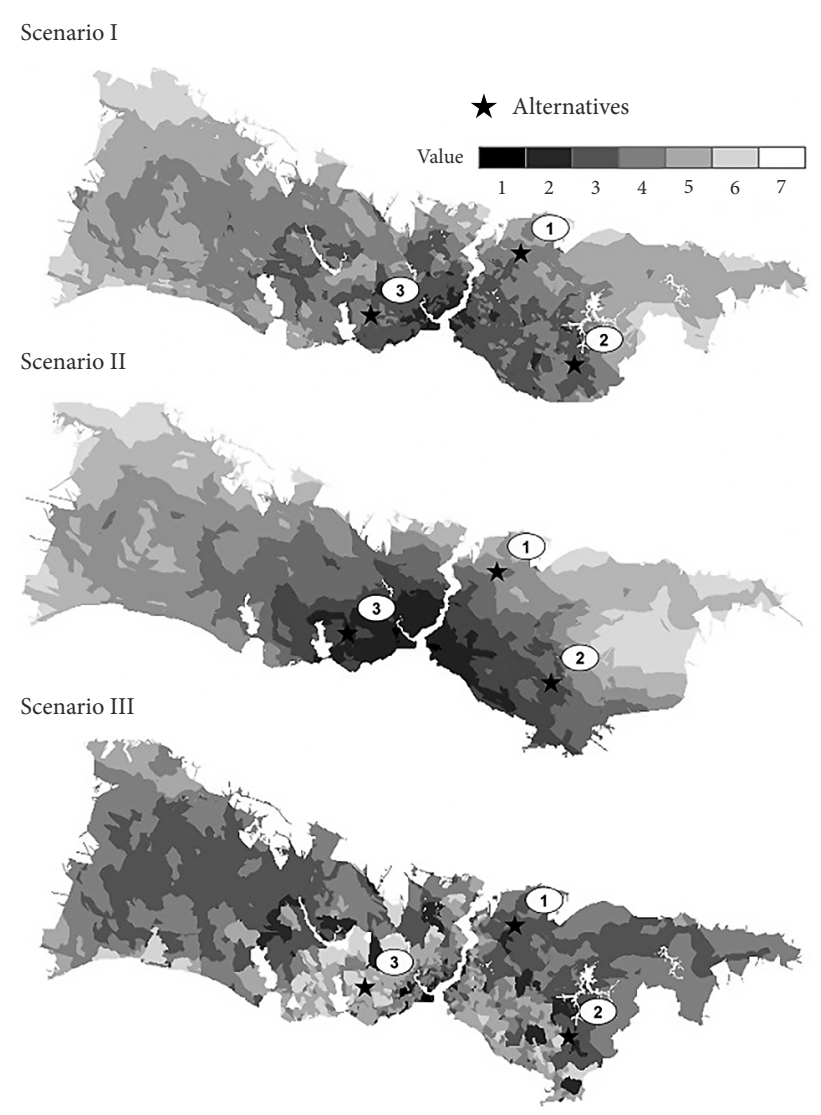

Figure 8. Result maps of sensitivity analysis of Method II

the Method I; but the difference between the alternatives showed significance in the Method II. The suitability values showed the success levels in selection process of Method II. The third alternative is found in the best preference level. It can be inferred from this finding, in case of small changes that have significant influences, the Method I is capable of representing the differences in more detail.

In Method I, the F-AHP employs pairwise comparisons; thus, enormous numbers of the alternatives cannot be considered with this method. But, the second method focuses continuous plane instead of a set of alternatives

Table 7. Scenario results of Method I

\begin{tabular}{|c|c|c|c|c|c|c|}
\cline { 2 - 7 } \multicolumn{1}{c|}{} & \multicolumn{2}{c|}{ Scenario I } & \multicolumn{2}{c|}{ Scenario II } & \multicolumn{2}{c|}{ Scenario III } \\
\hline Alternatives & Preference rank & Preference order & Preference rank & Preference order & Preference rank & Preference order \\
\hline A1 & 0.299 & 3 & 0.178 & 3 & 0.481 & 1 \\
\hline A2 & 0.302 & 2 & 0.340 & 2 & 0.244 & 2 \\
\hline A3 & 0.332 & 1 & 0.399 & 1 & 0.233 & 3 \\
\hline
\end{tabular}

Table 8. Scenario results of Method II

\begin{tabular}{|c|c|c|c|c|c|c|}
\cline { 2 - 7 } \multicolumn{1}{c|}{} & \multicolumn{2}{c|}{ Scenario I } & \multicolumn{2}{c|}{ Scenario II } & \multicolumn{2}{c|}{ Scenario III } \\
\hline Alternatives & Suitability value & Preference order & Suitability value & Preference order & Suitability value & Preference order \\
\hline A1 & 6 & 3 & 6 & 3 & 7 & 1 \\
\hline A2 & 7 & $1 / 2$ & 7 & 2 & 7 & 1 \\
\hline A3 & 7 & $1 / 2$ & 8 & 1 & 3 & 2 \\
\hline
\end{tabular}


that makes the approach capable for any number of alternatives. In the study, suitability ranks of 113500 are calculated and if it is necessary dealing with higher numbers is possible with Method II. All in all, both methods reached the same preference orders, and have different strengths in calculation.

For future studies, researchers can focus on the impacts of using different MC applications such as TOPSIS, PROMETHEE, etc., to understand if the methods can point the same results. Additionally using type- 2 interval fuzzy numbers and its applications during integration of GIS would be interesting to deal if the membership degree cannot be determined in location studies.

\section{References}

Brody, S. D.; Grover, H.; Bernhardt, S.; Tang, Z.; Whitaker, B.; Spence, C. 2006. Identifying potential conflict associated with oil and gas exploration in Texas state coastal waters: a multicriteria spatial analysis, Environmental Management 38(4): 597-617. https://doi.org/10.1007/s00267-005-0265-4

Buckley, J. J. 1985. Fuzzy hierarchical analysis, Fuzzy Sets and Systems 17(3): 233-247. https://doi.org/10.1016/0165-0114(85)90090-9

Chiang, D.; Guo, R.-S.; Chen, A.; Cheng, M.-T.; Chen, C.-B. 2007. Optimal supply chain configurations in semiconductor manufacturing, International Journal of Production Research 45(3): 631-651. https://doi.org/10.1080/00207540600792499

Chou, T.-Y.; Hsu, C.-L.; Chen, M.-C. 2008. A fuzzy multi-criteria decision model for international tourist hotels location selection, International Journal of Hospitality Management 27(2): 293-301. https://doi.org/10.1016/j.ijhm.2007.07.029

Dağdeviren, M. 2008. Decision making in equipment selection: an integrated approach with AHP and PROMETHEE, Journal of Intelligent Manufacturing 19(4): 397-406. https://doi.org/10.1007/s10845-008-0091-7

Delgado, M. G.; Sendra, J. B. 2004. Sensitivity analysis in multicriteria spatial decision-making: a review, Human and Ecological Risk Assessment: An International Journal 10(6): 11731187. https://doi.org/10.1080/10807030490887221

Eldemir, F.; Onden, I. 2016. Geographical information systems and multicriteria decisions integration approach for hospital location selection, International Journal of Information Technology \& Decision Making 15(5): 975-997.

https://doi.org/10.1142/S0219622016500218

Elevli, B. 2014. Logistics freight center locations decision by using Fuzzy-PROMETHEE, Transport 29(4): 412-418. https://doi.org/10.3846/16484142.2014.983966

Erdogan, S.; Yilmaz, I.; Baybura, T.; Gullu, M. 2008. Geographical information systems aided traffic accident analysis system case study: city of Afyonkarahisar, Accident Analysis \& Prevention 40(1): 174-181. https://doi.org/10.1016/j.aap.2007.05.004

ESRI. 2014. How hot spot analysis (Getis-Ord Gi*) works, in ArcGIS Help 10.2, 10.2.1, and 10.2.2. ArcGIS Resources. ESRI, Redlands, California, US. Available from Internet: http://resources.arcgis.com/en/help/main/10.2/index. html\#//005p00000011000000

Getis, A.; Ord, J. K. 1992. The analysis of spatial association by use of distance statistics, Geographical Analysis 24(3): 189206. https://doi.org/10.1111/j.1538-4632.1992.tb00261.x
Hecht, B.; Moxley, E. 2009. Terabytes of Tobler: evaluating the first law in a massive, domain-neutral representation of world knowledge, Lecture Notes in Computer Science 5756: 88-105. https://doi.org/10.1007/978-3-642-03832-7_6

Hsieh, T.-Y.; Lu, S.-T.; Tzeng, G.-H. 2004. Fuzzy MCDM approach for planning and design tenders selection in public office buildings, International Journal of Project Management 22(7): 573-584. https://doi.org/10.1016/j.ijproman.2004.01.002

Jankowski, P. 1995. Integrating geographical information systems and multiple criteria decision-making methods, International Journal of Geographical Information Systems 9(3): 251-273. https://doi.org/10.1080/02693799508902036

Jankowski, P. Richard, L. 1994. Integration of GIS-based suitability analysis and multicriteria evaluation in a spatial decision support system for route selection, Environment and Planning B: Urban Analytics and City Science 21(3): 323-340. https://doi.org/10.1068/b210323

Jenks, G. F. 1967. The data model concept in statistical mapping, International Yearbook of Cartography 7: 186-190.

Kampf, R.; Průša, P.; Savage, C. 2011. Systematic location of the public logistic centres in Czech Republic, Transport 26(4): 425-432. https://doi.org/10.3846/16484142.2011.635424

Kuo, R. J.; Chi, S. C.; Kao, S. S. 2002. A decision support system for selecting convenience store location through integration of fuzzy AHP and artificial neural network, Computers in Industry 47(2): 199-214. https://doi.org/10.1016/S0166-3615(01)00147-6

Levine, N. 2006. Crime Mapping and the CrimeStat program, Geographical Analysis 38(1): 41-56. https://doi.org/10.1111/j.0016-7363.2005.00673.x

Lin, C.-T. Tsai, M.-C. 2009. Development of an expert selection system to choose ideal cities for medical service ventures, $E x$ pert Systems with Applications 36(2): 2266-2274. https://doi.org/10.1016/j.eswa.2007.12.056

Malczewski, J. 1999. GIS and Multicriteria Decision Analysis. Wiley. $408 \mathrm{p}$.

Mon, D.-L.; Cheng, C.-H.; Lin, J.-C. 1994. Evaluating weapon system using fuzzy analytic hierarchy process based on entropy weight, Fuzzy Sets and Systems 62(2): 127-134. https://doi.org/10.1016/0165-0114(94)90052-3

Önden, İ.; Acar, A.; Eldemir, F. 2018. Evaluation of the logistics center locations using a multi-criteria spatial approach, Transport 33(2): 322-334. https://doi.org/10.3846/16484142.2016.1186113

Önden, İ.; Eldemir, F.; Çanc1, M. 2015. Lojistik merkez kavrami ve yer seçimine etki eden karar kriterleri [Logistics center concept and location decision criteria], Sigma Journal Engineering and Natural Sciences - Sigma Mühendislik ve Fen Bilimleri Dergisi 33(3): 325-340. (in Turkish).

Özceylan, E.; Erbaş, M.; Tolon, M.; Kabak, M.; Durğut, T. 2016. Evaluation of freight villages: a GIS-based multi-criteria decision analysis, Computers in Industry 76: 38-52. https://doi.org/10.1016/j.compind.2015.12.003

Saaty, T. L. 1980. The Analytic Hierarchy Process: Planning, Priority Setting, Resource Allocation. McGraw-Hill. 287 p.

Saaty, T. L. 2008. Decision making with the analytic hierarchy process, International Journal of Services Sciences 1(1): 83-98. https://doi.org/10.1504/IJSSCI.2008.017590

Soltani, A. Marandi, E. Z. 2011. Hospital site selection using twostage fuzzy multi-criteria decision making process, Journal of Urban and Environmental Engineering5(1): 32-43. https://doi.org/10.4090/juee.2011.v5n1.032043 
Tobler, W. R. 1970. A Computer movie simulating urban growth in the Detroit region, Economic Geography 46: 234-240. https://doi.org/10.2307/143141

Truong, L. T.; Somenahalli, S. V. C. 2011. Using GIS to identify pedestrian-vehicle crash hot spots and unsafe bus stops, Journal of Public Transportation 14(1): 99-114. http://doi.org/10.5038/2375-0901.14.1.6

Vahidnia, M. H.; Alesheikh, A. A.; Alimohammadi, A. 2009. Hospital site selection using fuzzy AHP and its derivatives, Journal of Environmental Management 90(10): 3048-3056. https://doi.org/10.1016/j.jenvman.2009.04.010

Zolfani, S. H.; Esfahani, M. H.; Bitarafan, M.; Zavadskas, E. K.; Arefi, S. L. 2013. Developing a new hybrid MCDM method for selection of the optimal alternative of mechanical longitudinal ventilation of tunnel pollutants during automobile accidents, Transport 28(1): 89-96. https://doi.org/10.3846/16484142.2013.782567

Zucca, A.; Sharifi, A.M.; Fabbri, A.G. 2008. Application of spatial multi-criteria analysis to site selection for a local park: a case study in the Bergamo Province, Italy, Journal of Environmental Management 88(4): 752-769.

https://doi.org/10.1016/j.jenvman.2007.04.026 